\title{
Endoscopic Retrograde Cholangio-Pancreatography in Patients with Liver Cirrhosis
}

\section{Mohamed AA Bassiony*}

Zagazig University, Zagazig, Egypt

*Corresponding author: Bassiony MAA, Zagazig University, Ash Sharqia Governorate 44519, Egypt, Tel: +20 55 2364612; E-mail: dr_mbh13303@yahoo.com

Received Date: February 23, 2018; Accepted Date: February 27, 2018; Published Date: March 8, 2018

Copyright: (c) 2018 Mohamed AA Bassiony. This is an open-access article distributed under the terms of the Creative Commons Attribution License, which permits unrestricted use, distribution, and reproduction in any medium, provided the original author and source are credited.

\begin{abstract}
Endoscopic retrograde cholangio-pancreatography (ERCP) is an endoscopic technique to diagnose and treat variable pancreatic and biliary disorders. Liver cirrhosis increases the incidence of cholelithiasis, intrahepatic cholangiocarcinoma and pancreatic carcinoma. Post- ERCP bleeding and pancreatitis are the most common complications in those population.
\end{abstract}

Keywords: ERCP; Cirrhosis; Pancreatitis; Post-ERCP bleeding; Biliary stones

\section{Introduction}

ERCP was first described in adult then pediatric clinical practice in the late 1960 s and early 1970 s for diagnosis and treatment of hepatobiliary and pancreatic obstructive disorders. This revolutionary endoscopic procedure involved improved side-viewing duodenoscopes and successful cannulation of papilla of vater to inject a contrast dye inside the pancreatico-biliary trees and watching the dye distribution on a fluoroscopic screen [1].

With the overwhelming technical advancements in non-invasive diagnostic imaging in addition to advances in sphincterotomy and stenting techniques, ERCP is largely shifted in the past decade from a predominantly diagnostic procedure into being a therapeutic modality [2].

Liver cirrhosis increases the incidence of cholelithiasis by 3 folds. Pigmented and cholesterol gallstones are the commonest types. The risk factors for cholelithiasis and choledocholithiasis in cirrhotic patients include high indirect bilirubin, decreased bile acids, and gallbladder hypo motility. Also, chronic alcoholism, viral C cirrhosis, and non-alcoholic fatty liver disease are major risk factors [3].

Cirrhotic patients have a 2-fold higher incidence of intrahepatic cholangiocarcinoma especially patients with primary biliary cholangitis (PBC) or primary sclerosing cholangitis [4].

Pancreatic carcinoma as well as acute and chronic pancreatitis are more common in cirrhotic than the non-cirrhotic population with chronic alcoholism starting at young age is a major risk factor for both conditions $[5,6]$.

From the previous data, we realize that ERCP is a valuable diagnostic and therapeutic modality for pancreatico-biliary disorders in cirrhotic and non-cirrhotic patients. However, the well-known hepatic sequelae especially in advanced hepatic decompensation (late Child-B and Child-C scores) as coagulopathy, thrombocytopenia, excessive ascites, hydrothorax, renal impairment and even cardiomyopathy result in a significant challenge and risk when deciding to perform ERCP for those patients population regarding both the preceding anesthesia and during the procedure [7].

Zhang et al. identified MELD score more than 11.5 as the best cutoff value for predicting complications of ERCP in cirrhotic patient with choledocholithiasis. They stated that the rates of complications and mortality were not significantly different among patients with different Child-Pugh classifications and concluded that ERCP is an effective and safe procedure in cirrhotic patients with choledocholithiasis [8].

Here in this article, we will discuss in brief the common indications, contraindications and complications of ERCP in hepatic patients.

\section{Indications $[9,10]$}

- Treatment of biliary stones.

- Diagnosis and treatment of intra- and extra-hepatic portal biliopathy in cirrhotic patients with portal hypertension.

- Diagnosis of primary biliary cirrhosis and primary sclerosing cholangitis.

- Diagnosis of cancer ampulla of vater.

- ERCP with sphincterotomy is therapeutic for type I sphincter of Oddi dysfunction.

- ERCP with stent insertion is a palliative therapy for malignant biliary obstruction.

- Early ERCP reduces morbidity and mortality in severe biliary pancreatitis.

\section{Contraindications $[9,10]$}

- Severe cardiopulmonary disease.

- Recent myocardial infarction.

- Uncorrectable coagulation disorders especially when sphincterotomy is to be performed.

- Contrast dye hypersensitivity.

- Suspected pancreatic or biliary disorders without confirmation by other imaging studies.

- Acute pancreatitis without evidence of biliary obstruction. 
Citation: Bassiony MAA (2018) Endoscopic Retrograde Cholangio-Pancreatography in Patients with Liver Cirrhosis. Hepatol Pancreat Sci 2: 1000111. doi:10.4172/ 2573-4563.1000111

Page 2 of 2

\section{Complications [11-13]}

ERCP-related complications can be divided into two main groups:

Specific complications: Bleeding: Typically occurs after sphincterotomy. This is the most common and most serious complication in cirrhotic patients.

Pancreatitis: The most frequent complication of ERCP.

Cholangitis: due to manipulation of an obstructed biliary system.

Perforation: of the esophagus, stomach, duodenum, or jejunum (rare).

Stent-related complications: stenosis or migration.

General complications: Medication-related: contrast allergy or oversedation (hepatic encephalopathy) by benzodiazepines.

Cardio-pulmonary complications: aspiration, hypoxemia, gas embolism and cardiac dysrhythmia.

Electro-surgical hazards: Excessive cautery can lead to pancreatic or biliary perforation, while inadequate cautery increases the risk of bleeding (hemobilia).

Miscellaneous rare complications: gallstone ileus, colonic perforation, liver abscess, pneumothorax, impaction of retrieval baskets, biloma.

\section{References}

1. Sumit S, Cyrus P (2014) Endoscopic retrograde cholangiopancreatography. Clinical liver disease 4: 133-113.

2. Raman M (2017) Testing for chronic diarrhea. Adv Clin Chem 79: 199-244.

3. Acalovschi M (2014) Gallstones in patients with liver cirrhosis: Incidence, etiology, clinical and therapeutical aspects. World J Gastroenterol 20: 7277-7285.
4. Adler DG, Baron TH, Davila RE, Egan J, Hirota WK, et al. (2005) ASGE guideline: The role of ERCP in diseases of the biliary tract and the pancreas. Gastrointest Endosc 62: 1-8.

5. Zhou Y, Zhang X, Zhang XF (2009) ERCP in patients with liver cirrhosis: analysis of 156 cases. Chin J Hepatobiliary Surgery 15: 9.

6. Spicak J, Pulkertova A, Kralova-Lesna I, Suchanek P, Vitaskova M, et al. (2012) Alcoholic chronic pancreatitis and liver cirrhosis: Coincidence and differences in lifestyle. Pancreatology $12: 311-316$.

7. Glomsaker TB, Hoff G, Kvaløy JT, Søreide K, Aabakken L, Søreide JA, et al. (2013) Patient-reported outcome measures after endoscopic retrograde cholangiopancreatography: A prospective, multicentre study. Scand J Gastroenterol 48: 868-876.

8. Zhang J, Ye L, Zhang J, Lin M, He S, et al. (2015) MELD scores and ChildPugh classifications predict the outcomes of ERCP in cirrhotic patients with choledocholithiasis: A retrospective cohort study. Medicine (Baltimore) 94 : e433.

9. Cohen S, Bacon BR, Berlin JA, Fleischer D, Hecht GA, et al. (2002) National institutes of health, state of the science conference statement: ERCP for diagnosis and therapy. Gastrointest Endosc 56: 803-809.

10. Callery M, Stewart L (2017) Cholecystolithiasis and stones in the common bile duct. In blumgart's surgery of the liver, biliary tract and pancreas.

11. Kwon CI, Song SH, Hahm KB, Ko KH (2013) Unusual complications related to endoscopic retrograde cholangiopancreatography and its endoscopic treatment. Clin Endosc 46: 251-259.

12. Draganov PV, Forsmark CE (2008) Prospective evaluation of adverse reactions to iodine-containing contrast media after ERCP. Gastrointest Endosc 68: 1098-1101.

13. Testoni PA, Mariani A, Giussani A, Vailati C, Masci E, et al. (2010) Risk factors for post-ERCP pancreatitis in high- and low-volume centers and among expert and non-expert operators: A prospective multicenter study. Am J Gastroenterol 105: 753-1756. 